\title{
Gene Expression Profiling in Familial Adenomatous Polyposis Adenomas and Desmoid Disease
}

\author{
Nikola A. Bowden ${ }^{1,2}$, Amanda Croff ${ }^{1,2}$, Rodney J. Scott ${ }^{1,23}$ \\ ISchool of Biomedical Sciences, University of Newcastle, Callaghan, NSW, Australia, \\ 2 Hunter Medical Research Institute, New Lambton Heights, NSW, Australia, \\ 3Molecular Genetics, HAPS, New Lambton Heights, NSW, Australia
}

Key words: gene expression profiling, FAP, adenomos, desmoid tumours

Corresponding author: Rodney J. Scott, Hunter Medical Research Institute, Level 3 John Hunter Hospital, Lookout Rd, New Lambton Heights, NSW 2308, Australia, phone +61 2498556 63, fax +61 2498558 95, e-mail: rodney.scott@newcastle.edu.au

Submitted: 9 February 2007

Accepted: 25 April 2007

\begin{abstract}
Gene expression profiling is a powerful method by which alterations in gene expression can be interrogated in a single experiment. The disease familial adenomatous polyposis (FAP) is associated with germline mutations in the APC gene, which result in aberrant $\beta$-catenin control. The molecular mechanisms underlying colorectal cancer development in FAP are being characterised but limited information is available about other symptoms that occur in this disorder. Although extremely rare in the general population, desmoid tumours in approximately $10 \%$ of FAP patients. The aim of this study was to determine the similarities and differences in gene expression profiles in adenomas and compare them to those observed in desmoid tumours. Illumina whole genome gene expression BeadChips were used to measure gene expression in FAP adenomas and desmoid tumours. Similarities between gene expression profiles and mechanisms important in regulating formation of FAP adenomas and desmoid tumours were identified. This study furthers our understanding of the mechanisms underlying FAP and desmoid tumour formation.
\end{abstract}

\section{Introduction}

Familial adenomatous polyposis (FAP) is a rare form of colorectal cancer caused by germline mutations in the adenomatous polyposis coli (APC) gene. Approximately $70-90 \%$ of FAP patients have identifiable germline mutations in APC [1,2]. FAP is clinically characterized by the formation of hundreds to thousands of adenomas that carpet the entire colon and rectum [3]. Although initially benign the risk of malignant transformation increases with age such that, if left untreated, colorectal carcinoma usually develops before the age of 40 years [4].
Loss of APC results in dysregulation of the Wnt signalling pathway that leads to the constitutional activation of the transcription factor Tcf-4, which has been associated with adenoma formation [5]. Alterations in Wnt signalling cause stem cells to retain their ability to divide in the upper intestinal crypt, thereby forming monocryptal adenomas [6]. Eventually the adenomas may acquire metastatic potential, resulting in carcinoma development [7]. Not all adenomas will progress to malignant tumours; however, due to the abundance of adenomas carcinoma development is virtually assured [8].

Apart from the apparent loss of APC function, little is known about the molecular processes involved in 
adenoma initiation [6]. Similarly, the molecular events occurring during the transformation of adenomas into carcinomas are poorly understood, as are the mechanisms that underlie the development of extracolonic disease in FAP.

It is well established that FAP patients are susceptible to benign extra-colonic tumours, including desmoid tumours [3]. Although rare in the general population, desmoids occur in approximately $10 \%$ of FAP patients and they are the second most common cause of death [9]. Desmoid tumours are poorly encapsulated and consist of spindle-shaped fibroblast cells with varying quantities of collagen [10]. Despite their apparent inability to metastasize, desmoid tumours can be extremely aggressive [11].

It has been speculated that desmoid formation is a result of an abnormal wound healing response [12]. Desmoids can affect surrounding viscera, causing potentially fatal complications [13]. FAP-associated desmoid tumours are usually associated with germline APC mutations [14], but somatic APC mutations have been detected in sporadic desmoid tumours [15].

Microarray technology has an enormous potential for applications in the endeavour to better understand tumours and their development [16]. The ability to detect expression levels of thousands of genes can identify particular genes that are either up- or down-regulated in different tumour types [17]. Tumours that are currently categorized by similar morphology, such as desmoid tumours, may be more usefully divided into subtypes according to their expression profiles [18]. Particular expression profiles in tumours may also be capable of predicting the clinical outcome in specific patients in the early stages of tumour development [18]. In colorectal cancer, gene expression profiles of adenomas and adenocarcinomas have been compared and subsets of genes expressed at common levels in both lesions have been identified as well as expression patterns that are unique to each [19]. Gene expression profiling has the potential to identify factors involved in the malignant transformation of adenomas, and may aid in the diagnosis of benign versus malignant disease.

Although genome-wide expression studies have been reported on FAP adenomas and desmoid tumours, the present one of the first to compare the two tissue types. The first aim of this study was to identify distinct gene expression profiles for colorectal and stomach FAP adenomas and desmoid tumours. The second aim was to determine the similarity between the gene expression profiles in FAP adenomas and desmoid tumours to identify mechanisms important in regulating formation of these lesions. To achieve this, mRNA from normal colon, FAP stomach and colon adenomas and desmoid tumours was measured using whole human genome expression
BeadChips (Illumina). The findings of this study further our understanding of the mechanisms underlying FAP and desmoid tumour formation.

\section{Materials and methods}

\section{FAP adenoma and tumour tissue and controls}

Frozen adenoma tissue from 4 FAP patients was available for this study. Colorectal FAP adenoma $A$ was from an individual aged 40 at the time of surgery. Genetic testing revealed a heterozygous A5465T change in the APC gene, causing a missense change from aspartic acid to valine at position 1822 in the amino acid sequence. The specimen obtained for this study was obtained as a result of a proctocolectomy. The pathology report indicated that over 100 tubulovillous adenomas were present in the original specimen, with no evidence of invasive tumour. Patients $B, C$ and $D$ harboured the same frameshift mutation, a 4 base pair deletion at position 3462-3465 of the APC gene. Patient B was diagnosed with FAP at the age of 11 years, patient $C$ at 13 years of age, and patient $D$ at the age of 37 years. One gastric adenoma was obtained from patient $D$, in addition to a colonic adenoma. Normal colon tissue from 7 healthy individuals with no history of FAP or desmoid disease was used as a mixed reference sample for this study.

\section{Desmoid Disease Tissue}

Desmoid tumour tissue from two individuals was available for this study. Patient A had FAP-associated desmoid disease. There was a family history of FAP, but no known history of desmoid disease. The individual harboured a $1 \mathrm{bp}$ deletion in exon 15 of the APC gene resulting in a frameshift that introduced a premature stop codon at amino acid position 964. Patient B had a family history of FAP and desmoid disease. This patient harboured a $17 \mathrm{bp}$ duplication in exon 15 of the APC gene, which introduced a premature stop codon at amino acid position 1969. A previously established fibroblast cell line from a healthy individual with no history of FAP or desmoid disease was used as a control for this study. The fibroblast cell line was cultured in $1 \times$ Complete DMEM media at $37^{\circ} \mathrm{C}\left(5 \% \mathrm{CO}_{2}\right)$.

\section{RNA Extraction}

2-3 $\mathrm{mm}^{2}$ pieces of fresh frozen FAP adenoma and desmoid tumour tissue were cut from the original sample and transferred immediately to $1 \mathrm{ml}$ Trizol reagent (Invitrogen, USA). Similarly, approximately 1-10 × $10^{6}$ control fibroblast cells were lysed in $1 \mathrm{ml}$ Trizol reagent 
(Invitrogen, USA). RNA was extracted per manufacturer's instructions. The RNA pellet was washed with 75\% ethanol, before being dissolved in $20 \mu$ l water.

The total RNA was purified using a Qiagen RNeasy MiniElute Cleanup Kit as per manufacturer's instructions. The concentration of the purified total RNA samples was measured using a Quant-It RiboGreen RNA Assay Kit (Invitrogen, USA) and a fluorometer (Fluostar OPTIMA) as per manufacturer's instructions.

\section{RNA amplification}

To synthesise first and second strand CDNA and amplify biotinylated cRNA from the total RNA, an Illumina Totalprep RNA Amplification Kit was used as per manufacturer's instructions.

The purified cRNA samples were quantified to determine the volume required for the BeadChip hybridisation step via the Quant-iT RiboGreen RNA Assay Kit as described previously.

\section{Illumina BeadChip Procedure}

Hybridisation to the Illumina Sentrix 8 BeadChip was performed according to the manufacturer's instructions without modification. The Sentrix 8 BeadChips were read using an Illumina Beadarray reader (San Diego, CA, USA).

\section{Data Analysis}

Analysis and normalisation of expression data from the 24,000 transcripts was carried out using BeadStudio 2.0 (Illumina, San Diego, CA, USA). The t-test error model and cubic spline normalisation was used for all samples. A differential analysis was applied to all adenoma and tumour samples using the Illumina custom test of significance, utilising the mixed normal colon control as the reference group. GeneSpring 5.0 (Agilant, Santa Clara, CA, USA) used standard correlation and distance to create dendrograms (Experiment trees) to show relationships between gene expression profiles. A second dendrogram (Gene tree) was created for each gene list using standard correlation and distance to show relationships between the expression levels of genes across the groups.

\section{Results}

Gene expression data from over 23,000 genes on Illumina HumRef-8 BeadChips was analysed and normalised using Illumina BeadStudio 2.0 software. Cubic spline normalisation and the t-test error model were employed for all the FAP adenoma, normal colon
Table 1. Genes commonly up-regulated more than 2-fold in all FAP polyps compared to normal colon

\begin{tabular}{ll}
\hline Symbol & Gene Name \\
\hline $\begin{array}{l}\text { Transcription/Transcriptional Regulation } \\
\text { TBPL1 }\end{array}$ & TBP-like 1 \\
\hline $\begin{array}{l}\text { Other } \\
\text { ZCWCC2 }\end{array}$ & $\begin{array}{l}\text { Zinc finger, CW-type with coiled-coil domain 2 } \\
\text { KIAA1324 }\end{array}$ \\
FLJ20366 & $\begin{array}{l}\text { Hybal } \\
\text { ATOH8 }\end{array}$ \\
\hline
\end{tabular}

and desmoid tumour samples. Correlation analyses identified the average $R^{2}$ value of the duplicates for each sample as $0.950 \pm 0.04$. An average of each duplicate pair was then taken before additional analysis was carried out.

\section{Differential gene expression analysis in FAP adenomas and healthy colon tissue}

Differential analysis using the mixed normal colon control as the reference group was applied to all adenoma and tumour samples. Genes in each analysis were excluded if their fluorescence detection score was less than 0.99, and if their differential score was less than $13(p>0.05)$. From the genes that met the exclusion criteria, according to detection and differential scores, lists were generated for genes both up- and down-regulated more than 2-fold in the FAP adenoma samples compared to the mixed normal colon control. The genes commonly up- and downregulated across all the FAP adenomas are shown in Tables 1 and 2 and genes that were commonly up- or down-regulated across the 4 colorectal FAP adenomas only are shown in Tables 3 and 4 respectively.

Cluster analysis was performed using GeneSpring 5.0 software in order to further characterise the similarity across the FAP samples and to determine if there was differential gene expression compared to healthy colon tissue. The stomach FAP duplicates display profiles slightly distinct from the other FAP adenomas. The normal colon duplicate profiles are unique to all other profiles (Figure 1).

\section{Differential gene expression analysis in desmoid tumours and control fibroblasts}

The average expression in the desmoid tumours was compared to the control fibroblast cell line and significantly altered expression identified by differential gene expression analysis. Genes in each analysis were excluded if their fluorescence detection score was less 
Table 2. Genes commonly down-regulated more than 2-fold in all FAP polyps compared to normal colon

\begin{tabular}{|c|c|}
\hline Symbol & Gene Name \\
\hline \multicolumn{2}{|c|}{ Cell Cycle Control } \\
\hline РPР3СВ & Protein phosphatase 3 (formerly 2B), catalytic subunit, beta isoform (calcineurin A beta) \\
\hline \multicolumn{2}{|l|}{ Transport } \\
\hline SLC20A1 & Solute carrier family 20 (phosphate transporter), member 1 \\
\hline P2RX4 & Purinergic receptor P2X, ligand-gated ion channel, 4 , tv-2 \\
\hline \multicolumn{2}{|l|}{ Metabolism } \\
\hline PC & Pyruvate carboxylase, nuclear gene encoding mitochondrial protein, tv-2 \\
\hline PRSS3 & Protease, serine, 3 (mesotrypsin) \\
\hline ST6GALNAC6 & CMP-NeuAC: (beta)-N-acetylgalactosaminide (alpha) 2,6-sialyltransferase member IV \\
\hline \multicolumn{2}{|c|}{ Signal Transduction } \\
\hline IL2RG & Interleukin 2 receptor, gamma (severe combined immunodeficiency) \\
\hline TJP3 & Tight junction protein 3 (zona occludens 3) \\
\hline \multicolumn{2}{|l|}{ Cell Adhesion } \\
\hline CDC42 & Cell division cycle 42 (GTP binding protein, $25 \mathrm{kDa}$ ), tv-2 \\
\hline GSN & Gelsolin (amyloidosis, Finnish type), tv-2 \\
\hline TAGLN & Transgelin \\
\hline \multicolumn{2}{|l|}{ Apoptosis } \\
\hline DAPK3 & Death-associated protein kinase 3 \\
\hline \multicolumn{2}{|l|}{ Structural } \\
\hline KRT19 & Keratin 19 \\
\hline TPM2 & Tropomyosin 2 (beta) \\
\hline \multicolumn{2}{|l|}{ Other } \\
\hline CTGF & Connective tissue growth factor \\
\hline EPS8L2 & EPS8-like 2 \\
\hline LRRC 1 & Leucine rich repeat containing 1 \\
\hline NS5ATP13TP2 & NS5ATP13TP2 protein \\
\hline PTPRR & Protein tyrosine phosphatase, receptor type, R, tv-2 \\
\hline $\mathrm{RICHI}$ & RhoGAP interacting with CIP4 homologs 1 \\
\hline SMTN & Smoothelin, tv-2 \\
\hline
\end{tabular}

than 0.99, and if their differential score was less than 13 ( $p>0.05)$. Genes with differential expression and up- or down-regulated more than 2 -fold in the desmoid tumour samples compared to the normal fibroblast cell line were compiled into lists (Tables 5 and 6).

To reveal any correlation between the expression profiles of desmoid tumours and FAP adenomas, the data from each group were compared. In the upper dendrogram (Figure 2) it can be seen that all the FAP adenomas cluster in the same group. The desmoid tumours and the normal fibroblast cell line clustered in an entirely different group to the FAP samples. The FAP adenomas and the normal colon have distinct gene profiles compared to the desmoid tumours and the normal fibroblasts. Within the FAP adenomas, the stomach adenoma and the normal colon have slightly different gene profiles compared to the colorectal adenomas.

\section{Discussion}

In this study, 24K Illumina HumRef-8 BeadArrays were used to compare gene expression of FAP adenomas, desmoid tumours and normal fibroblasts. To date there have been a number of small scale gene expression studies on FAP adenoma tissue, the vast majority of which have employed immunohistochemistry (IHC). Most of these studies have been performed on individual genes 
Table 3. Genes commonly up-regulated 2-fold or more in colorectal FAP polyps compared to normal colon

\begin{tabular}{ll}
\hline Symbol & Gene Name \\
\hline Cell Cycle Control & \\
CCNB2 & Cyclin B2 \\
CDKN3 & Cyclin-dependent kinase inhibitor 3 \\
AURKB & Aurora kinase B \\
\hline
\end{tabular}

Cell Cycle

$\begin{array}{ll}\text { HCAP-G } & \text { Chromosome condensation protein } \mathrm{G} \\ \text { PRC1 } & \text { Protein regulator of cytokinesis 1, tv-1 } \\ \text { KIF2C } & \text { Kinesin family member 2C } \\ \text { CHC1 } & \text { Chromosome condensation 1 } \\ \text { SMC4L1 } & \text { SMC4 structural maintenance of chromosome 4-like 1 (yeast) } \\ \text { Pfs2 } & \text { DNA replication complex GINS protein PSF2 } \\ \text { RNASEH2A } & \text { Ribonuclease H2, large subunit }\end{array}$

Transcription/Transcriptional Regulation

$\begin{array}{ll}\text { FLJ20315 } & \text { Hypothetical protein FLJ20315 } \\ \text { TBPL1 } & \text { TBP-like 1 } \\ \text { LOC89958 } & \text { Hypothetical protein LOC89958 } \\ \text { HMGN1 } & \text { High-mobility group nucleosome binding domain 1 } \\ \text { ZNF22 } & \text { Zinc finger protein 22 (KOX 15) } \\ \text { PTTG1 } & \text { Pituitary tumour-transforming 1 } \\ \text { NFE2L3 } & \text { Nuclear factor (erythroid-derived 2)-like 3 } \\ \text { SOX9 } & \text { SRY (sex determining region Y)-box 9 (campomelic dysplasia, autosomal sex-reversal) }\end{array}$

Transport

SLC12A2 Solute carrier family 12 (sodium/potassium/chloride transporters) member 2

CLCA1 Chloride channel, calcium activated, family member 1

LCN2 Lipocalin 2 (oncogene 24p3)

Metabolism

$\begin{array}{ll}\text { SORD } & \text { Sorbitol dehydrogenase } \\ \text { TPRT } & \text { Trans-prenyltransferase } \\ \text { QTRT1 } & \text { Queuine tRNA-ribosyltransferase 1 (tRNA-guanine transglycosylase) } \\ \text { PAICS } & \text { Phosphoribosylaminoimidazole carboxylase, Phosphoribosylaminoimidazole succinocarboxamide synthetase } \\ \text { DPH2L2 } & \text { DPH2-like 2 (S. cerevisiae), tv-1 } \\ \text { ALOX5 } & \text { Arachidonate 5-lipoxygenase } \\ \text { IARS } & \text { Isoleucine-tRNA synthetase, tv-short } \\ \text { BRIX } & \text { BRIX } \\ \text { TK1 } & \text { Thymidine kinase 1, soluble }\end{array}$

Oncogenesis

EPHB2

BCL11A

MAP17

EphB2 (EPHB2), tv-1

GDF15

(

Membrane-associated protein 17

Growth differentiation factor 15

Signalling

RACGAP1 Rac GTPase activating protein 1

mRNA Processing

LSM5 LSM5 homolog, U6 small nuclear RNA associated (S. cerevisiae)

THOC3 THO complex 3

Cell Adhesion 
Table 3. Genes commonly up-regulated 2-fold or more in colorectal FAP polyps compared to normal colon

\begin{tabular}{ll}
\hline Symbol & Gene Name \\
\hline Translation & \\
UK114 & Translational inhibitor protein p14.5 \\
\hline Other & \\
ZCWCC2 & Zinc finger, CW-type with coiled-coil domain 2 \\
KIAA1324 & Mabal \\
FLJ10514 & Hypothetical protein FLJ10514 \\
ENC1 & Ectodermal-neural cortex (with BTB-like domain) \\
PTTG2 & Pituitary tumour-transforming 2 \\
C21 orf59 & Chromosome 21 open reading frame 59 \\
WDR12 & WD repeat domain 12 \\
LXN & Latexin protein \\
\hline Other & \\
KIAA1892 & KIAA1892 \\
KIAA1797 & KIAA1797 \\
GLCE & Glucuronyl C5-epimerase \\
KIAA0101 & KIAA0101 gene product \\
RRP46 & Exosome component Rrp46 \\
S100P & S100 calcium binding protein P \\
PRDX4 & Peroxiredoxin 4 \\
FLJ20366 & Hypothetical protein FLJ20366 \\
F12 & Coagulation factor XII (Hageman factor) \\
IGFBP2 & Insulin-like growth factor binding protein 2 (36kD) \\
GW112 & Differentially expressed in hematopoietic lineages \\
C10orf3 & Chromosome 10 open reading frame 3 \\
ATOH8 & Atonal homolog 8 (Drosophila) \\
MFN1 & Mitofusin 1, nuclear gene encoding mitochondrial protein, tv-2 \\
QPCT & Glutaminyl-peptide cyclotransferase (glutaminyl cyclase) \\
UBE2S & Ubiquitin-coniugating enzyme E2S \\
\hline
\end{tabular}
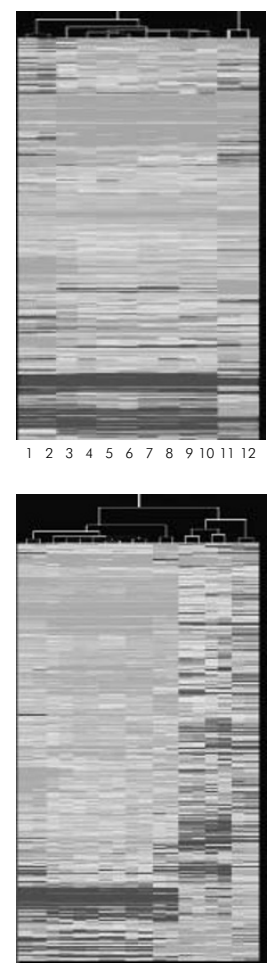

$2^{3} 4^{5} 6^{7} 8{ }^{9} 10^{11} 12^{13} 14^{15} 16^{17} 18$
Fig. 1. Cluster analysis of FAP polyps and mixed normal colon. The columns represent the gene expression profiles of each sample. Green - low expression level, yellow - medium expression level, red - high expression level. The relationships between each sample are shown by the upper dendrogram. The colouring in the upper dendrogram represents the sample type: green (left) - normal colon; blue - colorectal FAP polyps; yellow - stomach FAP. 1 - Normal Colon Duplicate; 2 - Normal Colon Duplicate; 3 - Colorectal FAP Polyp A Duplicate; 4 - Colorectal FAP Polyp A Duplicate; 5 - Colorectal FAP Polyp D Duplicate; 6 - Colorectal FAP Polyp D Duplicate; 7 - Colorectal FAP Polyp B Duplicate; 8 - Colorectal FAP Polyp B Duplicate; 9 - Colorectal FAP Polyp C Duplicate; 10 - Colorectal FAP Polyp C Duplicate; 11 - Stomach FAP Polyp D Duplicate; 12 - Stomach FAP Polyp D Duplicate

Fig. 2. Cluster analysis of FAP polyps, normal colon, desmoid tumours and normal fibroblasts. The columns represent the gene expression profiles of each sample. Green - low expression level, yellow - medium expression level, red high expression level. The relationships between each sample are shown by the upper dendrogram. The colouring in the upper dendrogram represents the sample type: green (left) - normal colon; blue - colorectal FAP polyps; orange - stomach FAP polyp; green (right) - desmoid tumours; purple - fibroblast cell line. 1 - Normal Colon Duplicate; 2 - Normal Colon Duplicate; 3 - Colorectal FAP Polyp A Duplicate; 4 - Colorectal FAP Polyp A Duplicate; 5 - Colorectal FAP Polyp D Duplicate; 6 - Colorectal FAP Polyp D Duplicate; 7 - Colorectal FAP Polyp B Duplicate; 8 - Colorectal FAP Polyp B Duplicate; 9 - Colorectal FAP Polyp C Duplicate; 10 - Colorectal FAP Polyp C Duplicate; 11 - Stomach FAP Polyp D Duplicate; 12 - Stomach FAP Polyp D Duplicate; 13 - Desmoid Tumour A Duplicate; 14 - Desmoid Tumour A Duplicate; 15 - Desmoid Tumour C Duplicate; 16 - Desmoid Tumour C Duplicate; 17 - Fibroblast Cell Line Duplicate; 18 - Fibroblast Cell Line Duplicate 
Table 4. Genes commonly down-regulated 2-fold or more in colorectal FAP polyps compared to normal colon

\begin{tabular}{ll}
\hline Symbol & Gene Name \\
\hline Cell Cycle Control & \\
FOSB & FBJ murine osteosarcoma viral oncogene homolog B \\
PPP3CB & Protein phosphatase 3, catalytic subunit, beta isoform (calcineurn A beta) \\
\hline Cell Cycle & \\
MXI1 & MAX interacting protein 1, tv-2 \\
CABLES1 & Cdk5 and Abl enzyme substrate 1 \\
PMP22 & Peripheral myelin protein 22, tv-3 \\
DTR & Diphtheria toxin receptor (heparin-binding epidermal growth factor-like growth factor) \\
\hline
\end{tabular}

Transcription/Transcriptional Regulation

$\begin{array}{ll}\text { HLX1 } & \text { H2.0-like homeo box } 1 \text { (Drosophila) } \\ \text { NKX2-3 } & \text { NK2 transcription factor related, locus } 3 \text { (Drosophila) } \\ \text { SOX18 } & \text { SRY (sex determining region Y)-box } 18 \\ \text { FNBP1 } & \text { Formin-binding protein 1 } \\ \text { COL4A1 } & \text { Collagen, type IV, alpha 1 } \\ \text { SIRT6 } & \text { Sirtuin (silent mating type information regulation } 2 \text { homolog) 6 (S. cerevisiae) } \\ \text { SIRT7 } & \text { Sirtuin (silent mating type information regulation } 2 \text { homolog) } 7 \text { (S. cerevisiae) } \\ \text { AIM1L } & \text { Absent in melanoma 1-like } \\ \text { C19orf21 } & \text { Chromosome 19 open reading frame } 21\end{array}$

Transport

FBXO32 F-box only protein 32, tv-2

KCNMA1 Potassium large conductance calcium-activated channel, subfamily $M$, alpha member 1

MYADM Myeloid-associated differentiation marker

AQP8 Aquaporin 8

SLC17A4 Solute carrier family 17 (sodium phosphate), member 4

SLCO2A1 Solute carrier organic anion transporter family, member 2A1

SGK Serum/glucocorticoid regulated kinase

P2RX4 Purinergic receptor P2X, ligand-gated ion channel, 4, tv-2

SLC20A1 Solute carrier family 20 (phosphate transporter), member 1

VAMP5 Vesicle-associated membrane protein 5 (myobrevin)

Metabolism

MGC4171

LIPH

KIAA0992

KIAA0828

SULT1A2

UPP1

BTNL3

KIAA0934

AK1

DPYSL3

PLCD 1

CA4

SVIL

PC

TMPRSS2

PRSS3

PCK1

ST6GALNAC6

RARRES2
Hypothetical protein MGC4171

Lipase, member $\mathrm{H}$

Palladin

KIAA0828 protein

Sulfotransferase family, cytosolic, 1A, phenol-preferring, member 2, tv-1

Uridine phosphorylase 1, tv-1

Butyrophilin-like 3, tv-2

KIAA0934 protein

Adenylate kinase 1

Dihydropyrimidinase-like 3

Phospholipase C, delta 1

Carbonic anhydrase IV

Supervillin, tv- 1

Pyruvate carboxylase, nuclear gene encoding mitochondrial protein, tv-2

Transmembrane protease, serine 2

Protease, serine, 3 (mesotrypsin)

Phosphoenolpyruvate carboxykinase 1 (soluble)

CMP-NeuAC: (beta)-N-acetylgalactosaminide (alpha)2,6-sialyltransferase member IV

Retinoic acid receptor responder (tazarotene induced) 2

Tumour Suppression 
Table 4. Genes commonly down-regulated 2-fold or more in colorectal FAP polyps compared to normal colon

\begin{tabular}{|c|c|}
\hline Symbol & Gene Name \\
\hline \multicolumn{2}{|l|}{ Signalling } \\
\hline RGL1 & Ral guanine nucleotide dissociation stimulator-like 1 \\
\hline EFNA1 & Ephrin-Al, tv-1 \\
\hline SDCBP2 & Syndecan binding protein (syntenin) 2, tv-2 \\
\hline GUCA2A & Guanylate cyclase activator 2A (guanylin) \\
\hline BSG & Basigin (OK blood group), tv-4 \\
\hline TRIF & TIR domain containing adaptor inducing interferon-beta \\
\hline ILK & Integrin-linked kinase \\
\hline TJP3 & Tight junction protein 3 (zona occludens 3) \\
\hline PRKCD & Protein kinase $\mathrm{C}$, delta \\
\hline ITPKA & Inositol 1,4,5-trisposphate 3-kinase A \\
\hline IL2RG & Interleukin 2 receptor, gamma (severe combined immunodeficiency) \\
\hline LNK & Lymphocyte adaptor protein \\
\hline \multicolumn{2}{|l|}{ Cell Adhesion } \\
\hline PC-LKC & Protocadherin LKC \\
\hline DCN & Decorin, tv-E \\
\hline FLNA & Filamin A, alpha (actin binding protein 280 ) \\
\hline MSN & Moesin \\
\hline SORBS 1 & Sorbin and $\mathrm{SH} 3$ domain containing 1 \\
\hline TAGLN & Transgelin \\
\hline CDC42 & Cell division cycle 42 (GTP binding protein, $25 \mathrm{kDa}$ ), tv-2 \\
\hline $\mathrm{COL} 4 \mathrm{~A} 2$ & Collagen, type IV, alpha 2 \\
\hline DBN1 & Drebin $1,+\mathrm{tv}-1$ \\
\hline GSN & Gelsolin (amyloidosis, Finnish type), tv-2 \\
\hline ACTG2 & Actin, gamma 2, smooth muscle, enteric \\
\hline ACTA2 & Actin, alpha 2, smooth muscle, aorta \\
\hline CGN & Cingulin \\
\hline \multicolumn{2}{|l|}{ Apoptosis } \\
\hline RIPK3 & Receptor-interacting serine-threonine kinase 3 \\
\hline FOSL2 & FOS-like antigen 2 \\
\hline DAPK3 & Death-associated protein kinase 3 \\
\hline LGALS 1 & Lectin, galactoside-binding, soluble, 1 (galactin 1) \\
\hline GADD45B & Growth arrest and DNA-damage-inducible, beta \\
\hline \multicolumn{2}{|l|}{ Structural } \\
\hline CLDN5 & Claudin 5 (transmembrane protein deleted in velocardiofacial syndrome) \\
\hline KRT19 & Keratin 19 \\
\hline TPM2 & Tropomyosin 2 (beta) \\
\hline \multicolumn{2}{|l|}{ Other } \\
\hline DUSP5 & Dual specificity phosphatase 5 \\
\hline CLIPR-59 & CLIP-170-related protein \\
\hline PTPRR & Protein tyrosine phosphatase, receptor type, R, tv-2 \\
\hline SMTN & Smoothelin, tv-2 \\
\hline CEACAM1 & Carcinoembryonic antigen-related cell adhesion molecule 1 (biliary glycoprotein) \\
\hline EPS8L2 & EPS8-like 2 \\
\hline $\mathrm{RICHI}$ & RhoGAP interacting with CIP4 homologs 1 \\
\hline PDZK2 & PDZ domain containing 2 \\
\hline CHKL & Choline kinase-like, tv- 1 \\
\hline DIP13B & DIP13 beta \\
\hline NS5ATP13TP2 & NS5ATP13TP2 protein \\
\hline M-RIP & Myosin phosphatase-Rho interacting protein \\
\hline MTMR9 & Myotubularin related protein 9 \\
\hline LRRC1 & Leucine rich repeat containing 1 \\
\hline CTGF & Connective tissue growth factor \\
\hline
\end{tabular}




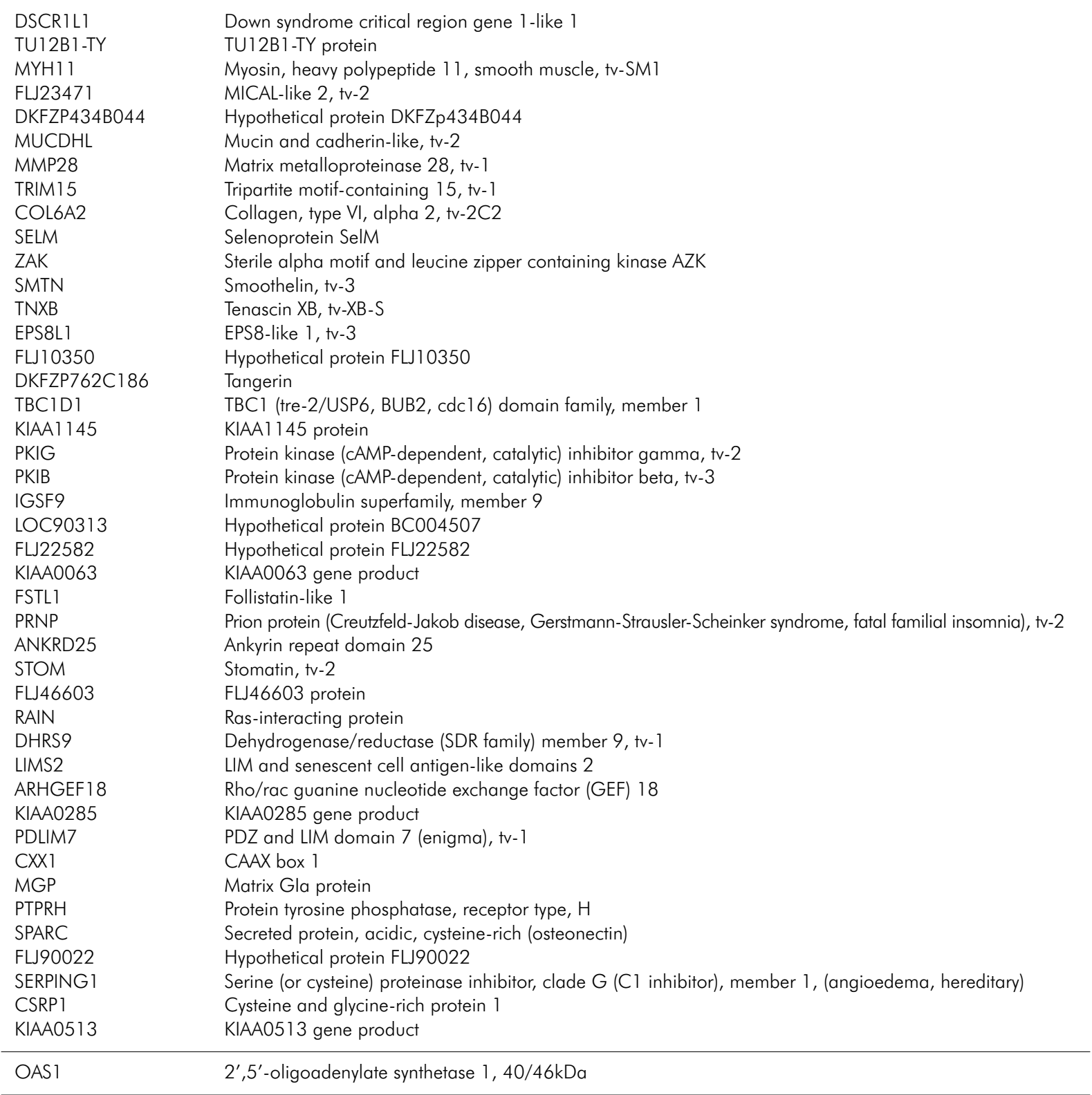

that include $E$-cadhein, $\alpha$-, $\beta$ - and $\gamma$-catenin, COX-1, COX-2, and c-myc [20-25]. In addition, one study used semi-quantitative RT-PCR to study GKLF [26]. The only report examining global gene expression in human FAP adenoma tissue identified 84 differentially expressed genes in adenomas compared to normal colon tissue [27].

In this study, the gene expression profiles obtained from the FAP adenomas indicate that colorectal adenomas are similar but distinctly different to the stomach adenomas. There were a large number of commonly expressed genes identified across the colorectal FAP adenomas, but when the differentially expressed genes from the stomach adenoma were included in the analysis the number of commonly expressed genes decreased dramatically. The genes that were differentially expressed in the four colonic adenomas and one stomach adenoma were investigated more closely in an attempt to identify common genetic features in FAP. From this analysis genes involved in the cell cycle, transcription and metabolism were the most frequently up-regulated. The most frequently down-regulated genes included those involved in metabolism, cell adhesion, signal transduction, transcription and transport. Since adenomas develop due to a breakdown in the fidelity of the Wnt signalling pathway it was not surprising to 
Table 5. Genes commonly up-regulated 2-fold or more in desmoid tumours compared to normal fibroblast cells

\begin{tabular}{ll}
\hline Symbol & Gene Name \\
\hline Cell Cycle Control & \\
PTN & Pleiotrophin (heparin binding growth factor 8, neurite growth-promoting factor 1) \\
GAS7 & Growth arrest-specific 7, tv-b \\
CDKN1C & Cyclin-dependent kinase inhibitor 1C (p57, Kip2) \\
TGFB3 & Transforming growth factor, beta 3 \\
\hline Cell Cycle & \\
NEK3 & NIMA (never in mitosis gene a)-related kinase 3, tv-2 \\
\hline
\end{tabular}

Transcription/Transcriptional Regulation

$\begin{array}{ll}\text { BHLHB2 } & \text { Basic helix-loop-helix domain containing, class B, 2 } \\ \text { COL4A1 } & \text { Collagen, type IV, alpha 1 } \\ \text { COL4A2 } & \text { Collagen, type IV, alpha 2 } \\ \text { DNAJB2 } & \text { DnaJ (Hsp40) homolog, subfamily B, member 2 } \\ \text { ELF2 } & \text { E74-like factor 2 (ets domain transcription factor), tv-1 } \\ \text { EVI1 } & \text { Ecotropic viral integration site 1 } \\ \text { FKBP1A } & \text { FK506 binding protein 1A, 12kDa, tv-12A } \\ \text { FLI10404 } & \text { Hypothetical protein FLJ10404 } \\ \text { HDAC8 } & \text { Histone deacetylase } 8 \\ \text { JUN } & \text { V-jun sarcoma virus 17 oncogene homolog (avian) } \\ \text { KIF2C } & \text { Kinesin family member C2 } \\ \text { NUCKS } & \text { Nuclear ubiquitous casein kinase and cyclin-dependent kinase substrate } \\ \text { PBX2 } & \text { Pre-B-cell leukemia transcription factor 2 } \\ \text { PPIE } & \text { Peptidylprolyl isomerase E (cyclophilin E), tv-2 } \\ \text { PRR3 } & \text { Proline-rich polypeptide 3 } \\ \text { TEAD2 } & \text { TEA domain family member 2 } \\ \text { TLE2 } & \text { Transducin-like enhancer of split 2 (E(sp 1)) homolog, Drosophila } \\ \text { TLE4 } & \text { Transducin-like enhancer of split 4 (E(sp 1)) homolog, Drosophila } \\ \text { ZNF22 } & \text { Zinc finger protein 22 (KOX15) } \\ \text { ZNF254 } & \text { Zinc finger protein 254 } \\ \text { TDRD3 } & \text { Tudor domain containing 3 } \\ \text { ZNF300 } & \text { Zinc finger protein 300 } \\ \text { MEF2C } & \text { MADS box transcription enhancer factor 2, polypeptide C (myocyte enhancer factor 2C) } \\ \text { NAB1 } & \text { NGFI-A binding protein 1 (EGR1 binding protein 1) } \\ \text { Hes4 } & \text { bHLH factor Hes4 } \\ \text { C19orf13 } & \text { Chromosome 19 open reading frame 13 } \\ \text { ARNT } & \text { Aryl hydrocarbon receptor nuclear translocator, tv-2 } \\ \text { ZNF266 } & \text { Zinc finger protein 266 } \\ \text { ZNF26 } & \text { Zinc finger protein 26 (KOX 20) } \\ \text { MGC51082 } & \text { Hypothetical protein MGC51082 } \\ \text { TGIF2 } & \text { TGFB-induced factor 2 (TALE family homeobox) } \\ \text { MYST3 } & \text { MYST histone acetyltransferase (monocytic leukemia) 3 } \\ \text { M96 } & \text { Likely ortholog of mouse metal response element binding transcription factor 2 } \\ \text { BAZ2B } & \text { Bromodomain adjacent to zinc finger domain, 2B } \\ & \end{array}$

Transport

NXT1

$\mathrm{ABCA} 1$

SLC25A29

SLC16A9

PSCD1

AQP1

SCNNID

SLC22A 17
Basic helix-loop-helix domain containing, class $B, 2$

Collagen, type IV, alpha

E74-like factor 2 (ets domain transcription factor), tv- 1

Ecotropic viral integration site

Histone deacetylase 8

molog (avian)

Pre-B-cell leukemia transcription factor 2

Transducin-like enhancer of split 2 (E(sp 1)) homolog, Drosophila

Zinc finger protein 22 (KOX 15 )

Zinc finger protein 254

Zindor domain containing 3

MADS box transcription enhancer factor 2, polypeptide $C$ (myocyte enhancer factor 2C)

NGFI-A binding protein 1 (EGRI binding protein 1$)$

Aryl hydrocarbon receptor nuclear translocator, tv-2

MYST histone acetyltransferase (monocytic leukemia) 3

Bromodomain adjacent to zinc finger domain, 2B

Metabolism

NTF2-like export factor 1

ATP-binding cassette, sub-family A, member 1

Solute carrier family 25, member 29

Solute carrier family 16 (monocarboxylic acid transporters), member 9

Pleckstrin homology, Sec7 and coiled-coil domains 1(cytohesin 1), tv-2

Aquaporin 1 (Channel-forming integral protein, 28kDa) tv-1

Sodium channel, nonvoltage-gated, delta

Solute carrier family 22 (organic cation transporter), member 17, tv-2

$\mathrm{CH} 25 \mathrm{H}$

Sulfotransferase family, cyłosolic, 1A, phenol-preferring, member 1, tv-1

Cholesterol 25-hydroxylase 
Table 5. Genes commonly up-regulated 2-fold or more in desmoid tumours compared to normal fibroblast cells

\begin{tabular}{ll}
\hline Symbol & Gene Name \\
\hline QTRTD1 & Queuine tRNA-ribosyltransferase domain containing 1 \\
FL23749 & Hypothetical protein FLJ23749 \\
FLJ10706 & Hypothetical protein FLJ10706 \\
USP52 & Ubiquitin specific protease 52 \\
RARRES2 & Retinoic acid receptor responder (tazarotene induced) 2 \\
ADAM19 & A distintegrin and metalloproteinase domain 19 (meltrin beta), tv-2 \\
AUTS2 & Autism susceptibility candidate 2 \\
GALNT3 & UDP-N-acetyl-alpha-D-galactosamine:polypeptide N-acetylgalactosaminyltransferase 3 (GalNAc-T3) \\
KIAA0140 & KIAA0140 \\
ODC-p & Ornithine decarboxylase-like \\
PCSK5 & Proprotein convertase subtilisin/kexin type 5 \\
\hline
\end{tabular}

Oncogenesis

$\begin{array}{ll}\text { AKAP13 } & \text { A kinase (PRKA) anchor protein 13, tv-3 } \\ \text { MGP } & \text { Matrix Gla protein } \\ \text { EWSR1 } & \text { Ewing sarcoma breakpoint region 1, tv-EWS-b } \\ \text { SFRP4 } & \text { Secreted frizzled-related protein } 4 \\ \text { SRPUL } & \text { Sushi-repeat protein }\end{array}$

Signalling

$\begin{array}{ll}\text { GABBR1 } & \text { Gamma-aminobutyric acid (GABA) B receptor, 1, tv-2 } \\ \text { CAPS } & \text { Calcyphosine, tv-2 } \\ \text { NET1 } & \text { Neuroepithelial cell transforming gene 1 } \\ \text { PRKCH } & \text { Protein kinase C, eta } \\ \text { PPP2R2B } & \text { Protein phosphatase 2 (formerly 2A), regulatory subunit B (PR52), beta isoform, tv-4 } \\ \text { RGS16 } & \text { Regulator of G-protein signalling 16 } \\ \text { PTHR1 } & \text { Parathyroid hormone receptor 1 } \\ \text { TMPEI } & \text { Transmembrane, prostate androgen induced RNA, tv-4 } \\ \text { ARHU } & \text { Ras homolog gene family, member U } \\ \text { CHN1 } & \text { Chimerin (chimaerin) 1 } \\ \text { EFNB3 } & \text { Ephrin-B3 } \\ \text { GFRA2 } & \text { GDNF family receptor alpha 2 } \\ \text { GNB4 } & \text { Guanine nucleotide binding protein (G protein), beta polypeptide } 4 \\ \text { IL1 1RA } & \text { Interleukin 11 receptor, alpha, tv-1 } \\ \text { ITPKB } & \text { Inositol 1,4,5-trisphosphate 3-kinase B } \\ \text { KIF13B } & \text { Kinesin family member 13B } \\ \text { MAP4K1 } & \text { Mitogen-activated protein kinase kinase kinase kinase 1 } \\ \text { MLP } & \text { MARCKS-like protein } \\ \text { PDGFRL } & \text { Platelet-derived growth factor receptor-like } \\ \text { PRKCABP } & \text { Protein kinase C, alpha binding protein } \\ \text { RASD1 } & \text { RAS, dexamethasone-induced 1 } \\ \text { TNFAIP6 } & \text { Tumour necrosis factor, alpha-induced protein 6 }\end{array}$

Cell Adhesion

COL7A1 Collagen, type VII, alpha 1 (epidermolysis bullosa, dystrophic, dominant and recessive) ISLR Immunoglobulin superfamily containing leucine-rich repeat, $\mathrm{tv}-1$

Apoptosis

PPP1R13B Protein phosphatase 1, regulatory (inhibitor) subunit 13B

AXUD1 AXIN1 up-regulated 1

CASP10 Caspase 10, apoptosis-related cysteine protease, tv-B

MX1 Myxovirus (influenza virus) resistance 1, interferon-inducible protein p78 (mouse)

PCBP4 Poly $(\mathrm{rC})$ binding protein $4, \mathrm{tv}-4$

TNFRSF19 Tumour necrosis factor receptor superfamily, member 19, tv-2

TNFRSF25 Tumour necrosis factor receptor superfamily, member 25, tv-7

Tumourigenesis

BARD1 BRCAl associated RING domain 1

LOH11CR2A Loss of heterozygosity, 11, chromosomal region 2, gene A 
Table 5. Genes commonly up-regulated 2-fold or more in desmoid tumours compared to normal fibroblast cells

\begin{tabular}{|c|c|}
\hline Symbol & Gene Name \\
\hline \multicolumn{2}{|c|}{ Immune Response } \\
\hline HLA-DPA 1 & Major histocompatibility complex, class II, DP alpha 1 \\
\hline $\mathrm{ClR}$ & Complement component $1, \mathrm{r}$ subcomponent \\
\hline CXCL14 & Chemokine (C-X-C motif) ligand 14 \\
\hline $\mathrm{IFI} 27$ & Interferon, alpha-inducible protein $27, \mathrm{tv}-\mathrm{a}$ \\
\hline MX2 & Myxovirus (influenza virus) resistance 2 (mouse) \\
\hline \multicolumn{2}{|c|}{ RNA Processing } \\
\hline DHX8 & DEAH (Asp-Glu-Ala-His) box polypeptide 8 \\
\hline HNRPA1 & Heterogeneous nuclear ribonucleoprotein $\mathrm{Al}, \mathrm{tv}-1$ \\
\hline SFRS 11 & Splicing factor, arginine/serine-rich 11 \\
\hline \multicolumn{2}{|l|}{ Structural } \\
\hline ACTL6 & Actin-like 6 \\
\hline FBLN1 & Fibulin 1 (FBLN1), tv-C \\
\hline FBLN1 & Fibulin 1 (FBLN1), tv-D \\
\hline SMTN & Smoothelin, tv-2 \\
\hline \multicolumn{2}{|l|}{ Other } \\
\hline MTIH & Metallothionein $1 \mathrm{H}$ \\
\hline C12orf14 & Chromosome 12 open reading frame 14 \\
\hline PELI 1 & Pellino homolog 1 (Drosophila) \\
\hline $\mathrm{IF} \mid 44$ & Interferon-induced protein 44 \\
\hline Cl0orf6 & Chromosome 10 open reading frame 6 \\
\hline C2orfl 1 & Chromosome 2 open reading frame 11 \\
\hline FLJ31951 & Hypothetical protein FLJ31951 \\
\hline ISYNAT & Myo-inositol 1 -phosphate synthase Al \\
\hline FLJ31614 & Hypothetical protein FLJ31614 \\
\hline AD031 & AD031 protein \\
\hline CASC3 & Cancer susceptibility candidate 3 \\
\hline GBA2 & Glucosidase, beta (bile acid) 2 \\
\hline CGI-85 & CGI-85 protein, tv-2 \\
\hline C14orf80 & Chromosome 14 open reading frame 80 \\
\hline ACAS2L & Acetyl-Coenzyme A synthetase 2 (AMP forming)-like, nuclear gene encoding mitochondrial protein \\
\hline DTX3 & Deltex 3 homolog (Drosophila) \\
\hline FLJ23059 & Hypothetical protein FLJ23059 \\
\hline PIK3RI & Phosphoinositide-3-kinase, regulatory subunit, polypeptide 1 (p85 alpha), tv-2 \\
\hline KIAA1223 & KIAA1223 \\
\hline STARD9 & START domain containing 9 \\
\hline LOC375786 & Hypothetical gene supported by AL713796 \\
\hline SR140 & U2-associated SR140 protein \\
\hline MIDN & Midnolin \\
\hline SEC31L2 & SEC31-like 2 (S. cerevisiae), tv-1 \\
\hline FLJ12178 & Hypothetical protein FLJ12178 \\
\hline LOC 157567 & Hypothetical protein LOC157567 \\
\hline FLJ25005 & FLJ25005 protein \\
\hline WARP & von Willebrand factor A domain-related protein, tv-1 \\
\hline KIAA1036 & KIAA1036 \\
\hline LOC374969 & Hypothetical protein LOC374969 \\
\hline LOC 155435 & Hypothetical protein LOC155435 \\
\hline MGC9913 & Hypothetical protein MGC9913 \\
\hline CASKIN2 & CASK interacting protein 2 \\
\hline CFDPI & Craniofacial development protein 1 \\
\hline SPAG5 & Sperm associated antigen 5 \\
\hline MMP23B & Matrix metalloproteinase 23B \\
\hline AKAP8L & A kinase (PRKA) anchor protein 8-like \\
\hline FLJ1 1029 & Hypothetical protein FLJ1 1029 \\
\hline DDIT4 & DNA-damage-inducible tv-4 \\
\hline APCDD1 & Adenomatous Polyposis Coli down-regulated 1 \\
\hline CDW92 & CDW92 antigen \\
\hline
\end{tabular}


Table 6. Genes commonly down-regulated 2-fold or more in desmoid tumours compared to normal fibroblast cells

\begin{tabular}{|c|c|}
\hline Symbol & Gene Name \\
\hline \multicolumn{2}{|l|}{ Cell Cycle } \\
\hline GRN & Granulin \\
\hline QSCN6 & Quiescin Q6 \\
\hline STAT1 & Signal transducer and activator of transcription $1,91 \mathrm{kDa}$, $\mathrm{tv}-\alpha$ \\
\hline STAT 1 & Signal transducer and activator of transcription 1,91 kDa, tv- $\beta$ \\
\hline TIMP1 & Tissue inhibitor of metalloproteinase 1 (erythroid potentiating activity, collagenase inhibitor) \\
\hline \multicolumn{2}{|c|}{ Transcription/Transcriptional Regulation } \\
\hline HIST1H2BK & Histone 1, H2bk \\
\hline LOXL 1 & Lysyl oxidase-like 1 \\
\hline MSC & Musculin (activated B-cell factor-1) \\
\hline PRRX1 & Paired related homeobox 1 , tv-pmx-1b \\
\hline $\mathrm{ZDHHC14}$ & Zinc finger, DHHC domain containing 14 \\
\hline \multicolumn{2}{|l|}{ Transport } \\
\hline GLRB & Glycine receptor, beta \\
\hline PCOLCE2 & Procollagen C-endopeptidase enhancer 2 \\
\hline SCAMP3 & Secretory carrier membrane protein $3, \mathrm{tv}-1$ \\
\hline SLC31A2 & Solute carrier family 31 (copper transporters), member 2 \\
\hline \multicolumn{2}{|l|}{ Metabolism } \\
\hline AK1 & Adenylate kinase 1 \\
\hline AKRIC3 & Aldo-keto reductase family 1, member C3 (3-alpha hydroxysteroid dehydrogenase, type II) \\
\hline CIRL & Complement component $1, r$ subcomponent-like \\
\hline COMT & Catechol-O-methyltransferase, tv-MB-COMT \\
\hline CTSL & Cathepsin L, tv-2 \\
\hline GCLM & Glutamate-cysteine ligase, modifier subunit \\
\hline GNPDA2 & Glucosamine-6-phosphate deaminase 2 \\
\hline $\mathrm{IDH} 1$ & Isocitrate dehydrogenase $1(\mathrm{NADP}+)$, soluble \\
\hline NQO1 & $\mathrm{NAD}(\mathrm{P}) \mathrm{H}$ dehydrogenase, quinone 1 \\
\hline PTGIS & Prostaglandin I2 (prostacyclin) synthase \\
\hline SMPDL3A & Sphingomyelin phosphodiesterase, acid-like $3 \mathrm{~A}$ \\
\hline SPPL2A & Putative intramembrane cleaving protease \\
\hline STS & Steroid sulfatase (microsomal), arylsulfatase $C$, isozyme S \\
\hline UBE2G1 & Ubiquitin-conjugating enzyme E2G 1 (UBC7 homolog, C. elegans), tv-1 \\
\hline $\mathrm{UCHL} 1$ & Ubiquitin carboxyl-terminal esterase L1 (ubiquitin thiolesterase) \\
\hline \multicolumn{2}{|c|}{ Tumour Suppression } \\
\hline MADH3 & MAD, mothers against decapentaplegic homolog 3 (Drosophila) \\
\hline \multicolumn{2}{|l|}{ Signalling } \\
\hline DEPDC6 & DEP domain containing 6 \\
\hline DIRASI & DIRAS family, GTP-binding RAS-like 1 \\
\hline PDGFRA & Platelet-derived growth factor receptor, alpha polypeptide \\
\hline PENK & Proenkephalin \\
\hline SARA2 & SARl a gene homolog 2 (S. cerevisiae) \\
\hline SNTB1 & Syntrophin, beta 1 (dystrophin-associated protein $\mathrm{Al}, 59 \mathrm{kDa}$, basic component 1) \\
\hline DKFZp564I1922 & Adlican \\
\hline \multicolumn{2}{|l|}{ mRNA Processing } \\
\hline CSTF1 & Cleavage stimulation factor, $3^{\prime}$ pre-RNA, subunit $1,50 \mathrm{kDa}$ \\
\hline \multicolumn{2}{|l|}{ Cell Adhesion } \\
\hline CNTNAP1 & Contactin-associated protein 1 \\
\hline THBS2 & Thrombospondin 2 \\
\hline ZYX & Zyxin \\
\hline
\end{tabular}


Table 6. Genes commonly down-regulated 2-fold or more in desmoid tumours compared to normal fibroblast cells

\begin{tabular}{|c|c|}
\hline Symbol & Gene Name \\
\hline \multicolumn{2}{|l|}{ Apoptosis } \\
\hline C20orf97 & Chromosome 20 open reading frame 97 \\
\hline DAPK 1 & Death-associated protein kinase 1 \\
\hline MAPK1 & Mitogen-activated protein kinase $1, \mathrm{tv}-1$ \\
\hline \multicolumn{2}{|l|}{ Structural } \\
\hline KRT18 & Keratin 18, tv-1 \\
\hline TUBG 1 & Tubulin, gamma 1 \\
\hline \multicolumn{2}{|c|}{ Immune Response } \\
\hline ANKRD15 & Ankyrin repeat domain $15, \mathrm{tv}-1$ \\
\hline DPP4 & Dipeptidylpeptidase 4 (CD26, adenosine deaminase complexing protein 2) \\
\hline MR1 & Major histocompatibility complex, class I-related \\
\hline \multicolumn{2}{|l|}{ Other } \\
\hline ANGPTL2 & Angiopoietin-like 2 \\
\hline ANTXR2 & Anthrax toxin receptor 2 \\
\hline $\mathrm{BCKDHB}$ & $\begin{array}{l}\text { Branched chain keto acid dehydrogenase } \mathrm{E} 1 \text {, beta polypeptide (maple syrup urine disease), nuclear gene } \\
\text { encoding mitochondrial protein, } \mathrm{tv}-2\end{array}$ \\
\hline BZRP & Benzodiazapine receptor (peripheral), tv-PBR-S \\
\hline C1 1orf17 & Chromosome 11 open reading frame 17, tv-2 \\
\hline C6orf32 & Chromosome 6 open reading frame 32 \\
\hline C9orf88 & Chromosome 9 open reading frame 88 \\
\hline CDC42EP2 & CDC42 effector protein (Rho GTPase binding) 2 \\
\hline CRLF1 & Cytokine receptor-like factor 1 \\
\hline DIRC2 & Disrupted in renal carcinoma 2 \\
\hline EDEM1 & ER degradation enhancer, mannosidase alpha-like 1 \\
\hline FLJ20073 & FLJ20073 protein \\
\hline FLJ20272 & Hypothetical protein FLJ20272 \\
\hline FLJ22582 & Hypothetical protein FLJ22582 \\
\hline HOM-TES- 103 & HOM-TES-103 tumour antigen-like, tv-3 \\
\hline HSPC157 & HSPC157 protein \\
\hline KIAA0196 & KIAA0196 gene product \\
\hline LOC196463 & Hypothetical protein LOC196463 \\
\hline LOC221091 & Similar to hypothetical protein \\
\hline LOC286343 & Hypothetical protein LOC286343 \\
\hline LOC387908 & Similar to Ferritin heavy chain (Ferritin $\mathrm{H}$ subunit) \\
\hline LOC57168 & Similar to aspartate beta hydroxylase (ASPH) \\
\hline LRRFIP2 & Leucine rich repeat (in FLII) interacting protein 2 \\
\hline LYPLAT & Lysophospholipase I \\
\hline MGC12992 & Hypothetical protein MGC12992 \\
\hline MGSTI & Microsomal glutathione S-transferase $1,+\mathrm{t}-1 \mathrm{a}$ \\
\hline MOCOS & Molybdenum cofactor sulfurase \\
\hline NNT & Nicotinamide nucleotide transhydrogenase \\
\hline PKM2 & Pyruvate kinase, muscle, tv-1 \\
\hline PPAP2B & Phosphatidic acid phosphatase type $2 \mathrm{~B}, \mathrm{tv}-2$ \\
\hline PSFL & Anterior pharynx defective 1B-like \\
\hline PTX3 & Pentaxin-related gene, rapidly induced by IL-1 beta \\
\hline S100A4 & S100 calcium binding protein A4 (calcium protein, calvasculin, metastasin, murine placental homolog), tv-2 \\
\hline SLIT3 & Slit homolog 3 (Drosophila) \\
\hline SMP1 & Small membrane protein 1 \\
\hline TRIM4 & Tripartite motif-containing 4 , tv- $\beta$ \\
\hline UNQ564 & UNQ564 \\
\hline ZC3HAV1 & Zinc finger $\mathrm{CCCH}$ type, antiviral $1, \mathrm{tv}-2$ \\
\hline
\end{tabular}


observe the over-expression of genes involved in cell cycle progression.

\section{Altered Expression of Wnt/ $\beta$-catenin Target Genes in Colorectal FAP Adenomas}

It has been long established that deregulation of the Wnt signalling pathway due to APC mutations plays a major role in the progression of FAP [5]. The Wnt/ $\beta$-catenin signalling pathway is involved in the control of expression of Sox9, PTTG1 and EphB2, all of which were found to be up-regulated by more than 2-fold in all the colorectal FAP adenomas compared to the normal colon.

PTTG1 is regulated by a TCF binding sequence in its promoter region [28]. The normal function of PTTG1 is to regulate chromosome segregation during cell division [29]. Over-expression of PTTG1 has been reported frequently in various types of cancer, including colorectal, and has been associated with angiogenesis [30-32]. The role of PTTG1 in angiogenesis is thought to be a result of its part in mediating the secretion of the basic fibroblast growth factor into the extracellular matrix, which promotes proliferation and migration of colorectal cancer cells [30, 31].

The Sox 9 gene encodes a transcription factor that is required for chondrogenesis and male gonad development [32], which is under the control of the Wnt signalling pathway [33]. The expression of the Sox9 gene in the intestine is dependent on the activity of the $\beta$-catenin/TCF-4 complex, although it is unknown whether this complex interacts directly with the Sox9 promoter or through another of its targets [33].

The EphB2 gene encodes the Eph receptor B, which has been shown to be a target of the Wnt signalling pathway [34]. There is evidence to suggest that normal patterning in the epithelium of the intestinal crypts is coordinated by EphB2 and its ligand, ephrin B [34]. Over-expression of EphB2 is often found in colorectal cancers, but there is confusion about its role in tumourigenesis. Many studies on other tumours have reported EphB2 over-expression as a marker of poor prognosis, but recent studies in colorectal cancer have suggested otherwise $[35,36]$.

\section{Altered Expression of Cell Cycle-Related Genes in Colorectal FAP Adenomas}

A number of genes found to be commonly upregulated in the adenomas used in this study have previously been reported as being over-expressed in various types of cancers. These genes include the cell cycle-related genes Chromosome condensation protein
G (HCAP-G), Protein regulator of cytokinesis 1 (PRC1), SMC4 structural maintenance of chromosome 4-like 1 (SMC4L1) and Cyclin B2 (CCNB2) [37-39]. Although these genes are associated with tumour development none have been thoroughly characterized in FAP to date.

\section{Altered Gene Expression in Desmoid Tumours}

A limited number of gene expression studies have been performed on desmoid tumours, primarily due to the difficulties in obtaining tissue. Two reports have studied gene expression in desmoid disease using 6.8K, $19 \mathrm{~K}$ and 33K Affymetrix microarrays $[40,41]$. Skubitz and Skubitz (2004) [40] reported that ADAM12, WISP-1, Sox- 11 and fibroblast activation protein- $\alpha$ are uniquely expressed in desmoids. Denys et al. (2004) identified 69 differentially expressed genes in desmoid tumour tissue compared to normal fibroblasts, before focusing on the down-regulation of IGFBP-6 [41].

A number of genes that were identified as being differentially expressed in desmoid tumours in this study have been reported previously. The over-expressed genes include transforming growth factor $\beta 3$ (TGF $\beta 3$ ), a distintegrin and metalloproteinase domain 19 (ADAM 19), chimerin $1(\mathrm{CHN1})$, and ephrin-B3 (EFNB3) $[40,41]$. The under-expressed genes include quiescin Q6 (QSCN6), prostaglandin 12 synthase (PTGIS), proenkephalin (PENK), keratin 18 (KRT18), cytokine receptor-like factor 1 (CRLF1), pentaxin-related gene (PTX3) and endoglin (ENG) [41].

\section{Ephrin-B3, a Wnt Target Overexpressed in Desmoid Tumours}

The known Wnt/ $\beta$-catenin target gene ephrin-B3 [42] has been found in this study to be up-regulated more than 2 -fold in desmoid tumours compared to normal fibroblasts. The ephrins are ligands for the EPH receptor family, whose normal function is to organize cell patterning in the intestinal crypts [34]. In addition, more recent observations suggest that ephrins are tumour suppressors, although the mechanism by which this is affected remains to be clarified [3, 43, 44]. Further investigation into the precise role of ephrin-B3 is required before any conclusions can be made regarding its role in desmoid disease.

\section{Wound Healing-Associated Genes Differentially Expressed in Desmoid Tumours}

Two genes, transforming growth factor $\beta$-3 (TGF $\beta 3$ ) and pleiotrophin (PTN), were found to be differentially expressed in desmoid tumours. Both genes are 
associated with wound healing and could potentially explain the growth advantage of desmoid tumours [45].

TGF $\beta 3$ is a multifunctional protein, having roles in cell proliferation and differentiation during embryogenesis and wound healing [46]. Pleiotrophin has been reported to be strongly expressed in many human cancers, and is thought to promote malignant transformation and angiogenesis [47]. It is also frequently found to be upregulated during the wound healing process [48].

In this study, three genes associated with negative regulation of the wound response have been identified as being under-expressed in desmoid tumours. The three genes are: signal transducer and activator of transcription 1 (STAT1), mothers against decapentaplegic homolog 3 (MADH3 or Smad3) and mothers against decapentaplegic homolog 6 (MADH6 or Smad6). STAT1 enhances transcription in response to interferon- $\gamma$, an action which has been shown to inhibit the wound healing response by preventing phosphorylation of Smad2 and Smad3 [49]. This in turn inhibits the action of TGF $\beta$ on the wound response [50]. The role of Smad3 in the wound response is not entirely understood; however, the absence of Smad3 causes an accelerated healing response, even though its over-expression has also been shown to promote healing [51, 52]. Smad6 is a known inhibitor of TGF $\beta$, and has shown to be down-regulated in keloids [53].

The abundance of wound response-related genes found to be deregulated in the desmoid tumours in this study adds to the notion that desmoid formation is an abnormal wound response. The finding of overexpressed genes involved in fibroblast proliferation and migration could explain the abnormal proliferation and local invasiveness of desmoid tumours. The downregulation of angiogenesis-associated genes could account for the poor vascularisation of desmoids.

The limiting factor in this study of desmoid tumours is the small number of desmoids available. In order to reach more conclusions regarding the exact molecular nature of desmoids and their growth mechanisms, a much larger sample size would be required.

\section{Comparison of FAP Adenoma and Desmoid Tumour Molecular Profiles}

It has long been recognized that desmoid tumours occur with a much higher frequency in FAP patients than in the general population. The apparent role of aberrant Wnt signalling in both diseases could indicate a molecular similarity between the two. Although Wnt target genes were identified as being up-regulated in both tumour types in this study, the specific genes were different in the two groups. The finding of different Wnt targets could be attributed to the use of different control groups for the FAP adenomas and desmoid tumours. Nevertheless, the molecular profiles obtained using cluster analysis clearly demonstrated that FAP adenomas and desmoid tumours display distinctly different gene expression profiles.

\section{Acknowledgements}

This work was supported in part by funds from the NBN Childhood Cancer Research Group, the University of Newcastle, the Clive and Vera Ramaciotti Centre for Gene Function Analysis, and the Hunter Medical Research Institute (HMRI).

\section{References}

1. Ponz de Leon M, Roncucci L. The cause of colorectal cancer. Dig Liver Dis 2000; 32: 426-439.

2. Sieber OM, Tomlinson IP, Lamlum $H$. The adenomatous polyposis coli (APC) tumour suppressor - genetics, function and disease. Mol Med Today 2000; 6: 462-469.

3. Giardiello F, Brensinger J, Petersen G. AGA technical review on hereditary colorectal cancer and genetic testing. Gastroenterology 2001; 121: 198-213.

4. Eccles DM, van der Luijt R, Breukel C, Bullman $H$, Bunyan D, Fisher A, Barber J, du Boulay C, Primrose J, Burn J, Fodde R. Hereditary desmoid disease due to a frameshift mutation at codon 1924 of the APC gene. Am J Hum Genet 1996; 59: 1193-1201.

5. Bonk T, Humeny A, Sutter C, Gebert J, von Knebel Doeberitz M, Becker C-M. Molecular diagnosis of familial adenomatous polyposis (FAP): genotyping of adenomatous polyposis coli (APC) alleles by MALDI-TOF mass spectrometry. Clin Biochem 2002; 35: 87-92.

6. Preston SL, Wong WM, Chan AO, Poulsom R, Jeffery R, Goodlad RA, Mandir N, Elia G, Novelli M, Bodmer WF, Tomlinson IP, Wright NA. Bottom-up histogenesis of colorectal adenomas: origin in the monocryptal adenoma and initial expansion by crypt fission. Cancer Res 2003; 63: 3819-3825.

7. Cruz-Correa M, Giardiello FM. Familial adenomatous polyposis. Gastrointest Endosc 2003; 58: 885-894.

8. Leslie A, Carey FA, Pratt NR, Steele RJ. The colorectal adenoma-carcinoma sequence. Br J Surg 2002; 89: 845-860.

9. Scates D, Clark S, Phillips R, Venitt S. Lack of telomerase in desmoids occurring sporadically and in association with familial adenomatous polyposis. Br J Surg 1998; 85: 965-969.

10. Reitamo J, Scheinin T, Hayry P. The desmoid syndrome. New aspects in the cause, pathogenesis and treatment of the desmoid tumor. Am J Surg 1986; 151 : 230-237.

11. Shields C, Winter D, Kirwan W, Redmond H. Desmoid Tumours. Eur J Surg Oncol 2001; 27: 701-706.

12. Cheon SS, Cheah AY, Turley S, Nadesan P, Poon R, Clevers H, Alman BA. beta-Catenin stabilization dysregulates mesenchymal cell proliferation, motility, and invasiveness and causes aggressive fibromatosis and hyperplastic cutaneous wounds. Proc Natl Acad Sci U S A 2002; 99: 6973-6978.

13. Brueckl WM, Ballhausen WG, Fortsch T, Gunther K, Fiedler W, Gentner B, Croner R, Boxberger F, Kirchner T, Hahn EG, Hohenberger W, Wein A. Genetic testing for germline mutations of the APC gene in patients with apparently sporadic desmoid tumors but a family history of colorectal carcinoma. Dis Colon Rectum 2005; 48: 1275-1281. 
14. Couture J, Mitri A, Lagace R, Smits R, Berk T, Bouchard HL, Fodde R, Alman B, Bapat B. A germline mutation at the extreme $3^{\prime}$ end of the APC gene results in a severe desmoid phenotype and is associated with overexpression of beta-catenin in the desmoid tumor. Clin Genet 2000; 57: 205-212.

15. Alman BA, Li C, Pajerski ME, Diaz-Cano S, Wolfe HJ. Increased beta-catenin protein and somatic APC mutations in sporadic aggressive fibromatoses (desmoid tumors). Am J Pathol 1997; 151: 329-334.

16. Cole KA, Krizman DB, Emmert-Buck MR. The genetics of cancer - a 3D model. Nat Genet 1999; 21 (1 Suppl): 38-41

17. Bucca G, Carruba G, Saetta A, Muti P, Castagnetta L, Smith CP. Gene expression profiling of human cancers. Ann N Y Acad Sci 2004; 1028: 28-37

18. Golub TR, Slonim DK, Tamayo P, Huard C, Gaasenbeek M, Mesirov JP, Coller H, Loh ML, Downing JR, Caligiuri MA, Bloomfield CD, Lander ES. Molecular classification of cancer: class discovery and class prediction by gene expression monitoring. Science 1999; 286: 531-537.

19. Lin Y-M, Furukawa Y, Tsunoda T, Yue C-T, Yang K-C, Nakamura Y. Molecular diagnosis of colorectal tumors by expression profiles of 50 genes expressed differentially in adenomas and carcinomas. Oncogene 2002; 21: 4120-4128.

20. Azumaya M, Kobayashi M, Ajioka Y, Honma T, Suzuki Y, Takeuchi M, Narisawa R, Asakura H. Size-dependent expression of cyclooxygenase-2 in sporadic colorectal polyps relative to adenomas in patients with familial adenomatous polyposis. Pathol Int 2002; 52: 272-276.

21. Brabletz T, Herrmann K, Jung A, Faller G, Kirchner T. Expression of nuclear beta-Catenin and c-myc is correlated with tumor size but not with proliferative activity of colorectal adenomas. Am J Pathol 2000; 156: 865-870

22. Brosens LA, lacobuzio-Donahue CA, Keller JJ, Hustinx SR, Carvalho R, Morsink FH, Hylind LM, Offerhaus GJ, Giardiello FM, Goggins M. Increased cyclooxygenase-2 expression in duodenal compared with colonic tissues in familial adenomatous polyposis and relationship to the $-765 \mathrm{G}->$ C COX-2 polymorphism. Clin Cancer Res 2005; 11: 4090-4096.

23. El-Bahrawy MA, Talbot IC, Poulsom R, Jeffery R, Alison MR. The expression of $\mathrm{E}$-cadherin and catenins in colorectal tumours from familial adenomatous polyposis patients. J Pathol 2002; 198: 69-76

24. Jungck M, Grunhage F, Spengler U, Dernac A, Mathiak M, Caspari R, Friedl W, Sauerbruch T. E-cadherin expression is homogeneously reduced in adenoma from patients with familial adenomatous polyposis: an immunohistochemical study of E-cadherin, beta-catenin and cyclooxygenase-2 expression. Int J Colorectal Dis 2004; 19: 438-445.

25. Khan KN, Masferrer JL, Woerner BM, Soslow R, Koki AT. Enhanced cyclooxygenase-2 expression in sporadic and familial adenomatous polyposis of the human colon. Scand J Gastroenterol 2001; 36: 865-869.

26. Dang DT, Bachman KE, Mahatan CS, Dang LH, Giardiello FM, Yang WW. Decreased expression of the gut-enriched Kruppel-like factor gene in intestinal adenomas of multiple intestinal neoplasia mice and in colonic adenomas of familial adenomatous polyposis patients. FEBS Lett 2000; 476: 203-207.

27. Salahshor S, Goncalves J, Chetty R, Gallinger S, Woodgett JR. Differential gene expression profile reveals deregulation of pregnancy specific beta 1 glycoprotein 9 early during colorecta carcinogenesis. BMC Cancer 2005; 5: 66.

28. Hlubek F, Pfeiffer S, Budczies J, Spaderna S, Jung A, Kirchner T, Brabletz T. Securin (hPTTG1) expression is regulated by beta-catenin/TCF in human colorectal carcinoma. Br J Cancer 2006 94: 1672-1677
29. Pfleghaar K, Heubes S, Cox J, Stemmann O, Speicher MR. Securin is not required for chromosomal stability in human cells. PLoS Biol 2005; 3: e416.

30. Fujii T, Nomoto S, Koshikawa K, Yatabe Y, Teshigawara O, Mori T, Inove S, Takeda S, Nakao A. Overexpression of pituitary tumor transforming gene 1 in $\mathrm{HCC}$ is associated with angiogenesis and poor prognosis. Hepatology 2006; 43: 1267-1275.

31. Heaney AP, Singson R, McCabe CJ, Nelson V, Nakashima M, Melmed S. Expression of pituitary-tumour transforming gene in colorectal tumours. Lancet 2000; 355: 716-719.

32. Cho-Rok J, Yoo J, Jang YJ, Kim S, Chu IS, Yeom YI, Choi JY, Im DS. Adenovirus-mediated transfer of siRNA against PTTG 1 inhibits liver cancer cell growth in vitro and in vivo. Hepatology 2006; 43: 1042-1052.

33. Drivdahl R, Haugk KH, Sprenger CC, Nelson PS, Tennant MK, Plymate SR. Suppression of growth and tumorigenicity in the prostate tumor cell line $\mathrm{M} 12$ by overexpression of the transcription factor SOX9. Oncogene 2004; 23: 4584-4593.

34. Blache P, van de Wetering M, Duluc I, Domon C, Berta P, Freund $\mathrm{JN}$, Clevers $\mathrm{H}$, Jay P. SOX9 is an intestine crypt transcription factor, is regulated by the Wnt pathway, and represses the CDX2 and MUC2 genes. J Cell Biol 2004; 166: 37-47

35. Batlle $E$, Henderson JT, Beghtel $H$, van den Born MM, Sancho $E$, Huls G, Meeldijk J, Robertson J, van de Wetering M, Pawson T, Clevers $\mathrm{H}$. Beta-catenin and TCF mediate cell positioning in the intestinal epithelium by controlling the expression of EphB/ephrinB. Cell 2002; 111: 251-263.

36. Nakada M, Niska J, Miyamori H, McDonough WS, Wu J, Sato H, Berens ME. The phosphorylation of EphB2 receptor regulates migration and invasion of human glioma cells. Cancer Res 2004; 64: 3179-3185.

37. Wu Q, Suo Z, Risberg B, Karlsson MG, Villman K, Nesland JM. Expression of Ephb2 and Ephb4 in breast carcinoma. Pathol Oncol Res 2004; 10: 26-33.

38. Jager D, Stockert E, Jager E, Gure AO, Scanlan MJ, Knuth A, Old LJ, Chen YT. Serological cloning of a melanocyte rab guanosine $5^{\prime}$-triphosphate-binding protein and a chromosome condensation protein from a melanoma complementary DNA library. Cancer Res 2000; 60: 3584-3591.

39. Li C, Lin M, Liu J. Identification of PRC1 as the p53 target gene uncovers a novel function of p53 in the regulation of cytokinesis. Oncogene 2004; 23: 9336-9347.

40. Sarafan-Vasseur N, Lamy A, Bourguignon J, Le Pessot F, Hieter P, Sesboue R, Bastard C, Frebourg T, Flaman JM. Overexpression of B-type cyclins alters chromosomal segregation. Oncogene 2002; 21 : 2051-2057

41. Skubitz KM, Skubitz AP. Gene expression in aggressive fibromatosis. J Lab Clin Med 2004; 143: 89-98.

42. Denys H, Jadidizadeh A, Amini Nik S, Van Dam K, Aerts S, Alman BA, Cassiman JJ, Tejpar S. Identification of IGFBP-6 as a significantly downregulated gene by beta-catenin in desmoid tumors. Oncogene 2004; 23: 654-664.

43. Katoh Y, Katoh M. Comparative integromics on Ephrin family. Oncol Rep 2006; 15: 1391-1395.

44. Jubb AM, Zhong F, Bheddah S, Grabsch HI, Frantz GD, Mueller W, Kavi V, Quirke P, Polakis P, Koeppen H. EphB2 is a prognostic factor in colorectal cancer. Clin Cancer Res 2005; 11: 5181-5187.

45. Guo DL, Zhang J, Yuen ST, Tsui WY, Chan AS, Ho C, Ji J, Leung SY, Chen X. Reduced expression of EphB2 that parallels invasion and metastasis in colorectal tumours. Carcinogenesis 2006; 27: 454-464.

46. Lee CH, Bang SH, Lee SK, Song KY, Lee IC. Gene expression profiling reveals sequential changes in gastric tubular adenoma and carcinoma in situ. World J Gastroenterol 2005; 11 : 1937-1945. 
47. Cox DA. Transforming growth factor-beta 3. Cell Biol Int 1995 ; 19: 357-371

48. Riegel AT, Wellstein A. The potential role of the heparin-binding growth factor pleiotrophin in breast cancer. Breast Cancer Res Treat 1994; $31:$ 309-314

49. Christman KL, Fang Q, Kim AJ, Sievers RE, Fok HH, Candia AF, Colley KJ, Herradon G, Ezquerra L, Deuel TF, Lee RJ. Pleiotrophin induces formation of functional neovasculature in vivo. Biochem Biophys Res Commun 2005; 332: $1146-1152$.

50. DaFonseca CJ, Shu F, Zhang JJ. Identification of two residues in MCM5 critical for the assembly of MCM complexes and Statl-mediated transcription activation in response to IFN-gamma. Proc Natl Acad Sci U S A 2001; 98: 3034-3039.

51. O'Kane S, Ferguson MW. Transforming growth factor beta s and wound healing. Int J Biochem Cell Biol 1997; 29: 63-78.

52. Falanga V, Schrayer D, Cha J, Butmarc J, Carson P, Roberts AB, Kim SJ. Full-thickness wounding of the mouse tail as a model for delayed wound healing: accelerated wound closure in Smad3 knock-out mice. Wound Repair Regen 2004; 12: 320-326.

53. Sumiyoshi K, Nakao A, Setoguchi Y, Okumura K, Ogawa H. Exogenous Smad3 accelerates wound healing in a rabbit dermal ulcer model. J Invest Dermatol 2004; 123: 229-236.

54. Yu H, Bock O, Bayat A, Ferguson MW, Mrowietz U. Decreased expression of inhibitory SMAD6 and SMAD7 in keloid scarring. J Plast Reconstr Aesthet Surg 2006; 59: 221 -229. 